\title{
O lugar da natureza no movimento Art Nouveau
}

\section{Miriam de Paiva Vieira, UFMG}

Resumo: Partindo da hipótese de que a exploração exacerbada dos ornamentos com motivos naturais característica do art nouveau, não seria uma reversão à natureza, e sim o prenúncio de uma aversão ao tema, este artigo objetiva a investigação do papel da natureza nesse movimento em voga na virada do século XIX para o século XX, para compreender qual é seu lugar do ponto de vista estético.

Palavras-chave: natureza; art nouveau; arquitetura.

O art nouveau é um movimento artístico de vanguarda, destituído de preocupações ideológicas. De inspiração romântica, independente de tradições estéticas, sua valorização do trabalho artesanal sinalizava a resistência ao progresso tecnológico comum ao momento decadentista. O art nouveau origina-se no movimento inglês arts and crafts, propondo uma concepção de "estilo total", com expressão em diversas áreas da arte, da arquitetura e da produção. O movimento art nouveau propicia o início do design gráfico e de produto, expressando-se em diferentes escalas, tais como arquitetura, interiores e artes decorativas, incluindo joalharia, mobiliário, têxteis, prata, utensílios e objetos de iluminação. De acordo com a filosofia de seus discípulos, "a arte deve ser um modo de vida"l.

O nome foi dado em Paris pela Maison de l'Art Nouveau, gerenciada pelo marchand de arte Samuel Bing (1838-1905). É descrito como "ornato, decorativo, assimétrico e de certa forma fantástico"2 pelo Dictionary of Literary Terms and Literary Theory. Uma das mais marcantes características do estilo é o seu aporte tipográfico, unindo letra e imagem por meio de uma profusão de linhas curvas naturais. Esta combinação foi utilizada em cartazes, capas de livros e anúncios. Apesar de não configurar estilo específico de escrita, influenciou ilustrações de obras literárias e certos movimentos literários, tais como os pré-rafaelitas e os simbolistas. O florescimento das artes e arquitetura aliado aos descobrimentos e avanços científicos e tecnológicos, em contraponto à postura negativista das correntes literárias do decadentismo, conferem um tom contraditório ao movimento art nouveau.

Todas as artes vitorianas se direcionam para a expressão da natureza que culmina no art nouveau. No entanto, os arquitetos seguidores do movimento foram os primeiros a retomar diretamente a natureza como forma de inspiração desde o período gótico. Os prérafaelitas preferem os efeitos de imitação, insistindo na cópia fiel do modelo, já os precursores do art nouveau reinterpretam os motivos naturais em duas dimensões para compor seus projetos, ou aceitam apenas formas derivadas da natureza na ornamentação da arquitetura. Em geral, os defensores do movimento vislumbram esse papel essencial da natureza.

A marca do art nouveau é o culto à linha curva emprestado do movimento neogótico. A linha curva busca a representação da natureza em antenas de insetos, caules, ou contornos das pétalas de uma flor, de modo a imobilizar algo que se move. Os temas 
preferidos são os motivos florais, as folhagens, a fertilidade da natureza, e ainda os de origem mística $^{3}$. A inspiração vem do Oriente e também das linhas do corpo humano, em especial as da mulher. Segundo Umberto Eco, a mulher da época, a femme fatale do fin de siècle, é sensual, eroticamente emancipada e ama a cosmética ${ }^{4}$. A maior diferenciação estética dos movimentos anteriores é a assimetria de suas formas.

Os princípios positivistas estabelecidos por Jean Schopfer ${ }^{5}$, entre os quais a afirmação de que "o art nouveau reverteu à natureza, o que pode revelar nova beleza", não só inspiram, mas propiciam as obras-primas dos grandes arquitetos da época. Entretanto, no apogeu da consolidação do modernismo, em meados do século XX, o art nouveau é considerado somente um estilo ornamental, com sua influência depreciada por muitos críticos.

No artigo The Nature and the Art Nouveau (1955), James Grady foi o primeiro a considerar a importância do tema da natureza no movimento, de acordo com Stephen Madsen ${ }^{7}$. Para Grady, o movimento foi o ápice da natureza como expressão estética, ocorrendo em um momento oportuno. Madsen completa o pensamento de Grady, chamando atenção para o fato de que a compreensão do papel da natureza no movimento art nouveau é um dos fundamentos essenciais para um melhor entendimento de seus artistas.

Apesar de temporalmente muito próximo ao movimento para avaliar sua importância, ou sua influência exata, Grady questiona se o movimento teria sido somente um parêntese inútil e frívolo, ou uma expressão válida que contribuiu com um novo ponto de vista para a estética. Ele conclui que o art nouveau teve uma maior influência do que se pensava até então, pois exerceu um importante papel de "ponte entre as confusas expressões arqueológicas do século XIX [que seriam os revivals ecléticos, tais como o neogótico, neoclássico e o orientalismo] e a arquitetura contemporânea" ${ }^{\text {. }}$. Nesse sentido, deixou um importante legado de valores ao desenvolvimento contemporâneo.

Susan Sontag, por sua vez, afirma que o movimento art-nouveau é o melhor exemplo das "coisas-que-são-como-não-são" em seu artigo dedicado a Oscar Wilde, Notes on Camp $^{10}$ (1964). Já no final dos anos oitenta, Leonardo Benevolo defende o art nouveau como o auge da natureza em expressão estética, fundamentado na declaração de um dos mais importantes precursores do movimento, o arquiteto Hector Guimard:

A natureza é um grande livro do qual podemos tirar inspiração, e é dentro desse que devemos buscar princípios, os quais, quando encontrados devem ser definidos e aplicados pela mente de acordo com as necessidades humanas. Mas a contribuição singular do final do século XIX é a metamorfose da natureza em todas as expressões estéticas do período ${ }^{11}$.

Ou seja, o tom contraditório do movimento art nouveau incita críticas também contraditórias ao longo dos tempos. Hoje, grande parte de seu legado é considerado patrimônio histórico e o movimento é validado pelas frequentes exposições dos objetos de design em renomadas galerias e museus em várias partes do mundo.

O objetivo deste artigo é investigar o papel da natureza no movimento art nouveau, para compreender qual é seu lugar do ponto de vista estético. Minha hipótese é a de que a exploração exacerbada dos ornamentos com motivos naturais não seria uma reversão à natureza, como estabelecido por Schopfer, e sim o prenúncio de uma aversão ao tema, em sintonia com o tom contraditório da cultura burguesa decadentista na virada do século XIX para o século XX - aversão essa que atinge seu auge no modernismo. 
O espírito da virada do século conta com dois momentos contraditórios: a postura negativista das correntes literárias do período conhecido como Fin de siècle (de 1880 a 1890), em oposição à paz e prosperidade, geradas pelos descobrimentos e avanços científicos e tecnológicos, que propiciaram o florescimento das artes e arquitetura do período seguinte, o Belle Époque (de 1890 a 1914). O tom dicotômico das expressões artísticas do movimento art nouveau é, portanto, o resultado dessa intempérie cultural característica do decadentismo.

$\mathrm{O}$ art nouveau é percebido no dia-a-dia mais do que em museus, estando presente em peças decorativas, na arquitetura e em equipamentos urbanos. A arquitetura proporciona a experiência estética por meio da mobilidade, apresentando dupla forma de recepção: uso e percepção, por meios táteis e óticos. Na medida em que a produção em série, ou a reprodutibilidade técnica de acordo com Benjamin, começa a substituir a produção artesanal em pequena escala, a perspectiva do consumo adquire uma qualidade utilitária, deixando de ser meramente contemplativa.

Em Paris do segundo império ${ }^{12}$, Walter Benjamin faz um apanhado do período decadentista. $\mathrm{O}$ autor alega que a burguesia buscava dentro de casa a privacidade perdida na vida da cidade grande. Essa burguesia tentava resgatar o passado nos artigos de consumo e acessórios: capas, estojos de chinelos, relógios de bolso, termômetros, talheres e guarda-chuvas. Os materiais preferidos eram aqueles que marcavam a experiência tátil, como o veludo e a pelúcia ${ }^{13}$. Uma vez que o modo de produção capitalista possibilitou a reprodução de obras de arte em série, o art nouveau abriu um novo mercado que promoveu uma maior acessibilidade ao belo. Mesmo aqueles que não tinham recursos financeiros para adquirir um vitral poderiam comprar uma luminária projetada pelo mesmo artesão e produzida com o mesmo material, levando assim a beleza para dentro de mais lares. A possibilidade da reprodutibilidade técnica da arte marca o início do design industrial.

Benjamin explica que "a moradia se torna uma espécie de cápsula. Concebe-a como um estojo do ser humano e nela o acomodam todos os seus pertences, assim, seus vestígios, como a natureza preserva no granito uma fauna extinta"14. Assim como na natureza, nenhuma folha é igual à outra, cada casa burguesa possui características impares que refletem a personalidade de seu dono. A burguesia tem receio de todas as mudanças provocadas pelos descobrimentos e avanços científicos e tecnológicos, que surgem como uma nova natureza ameaçadora. A segurança é, portanto, alcançada através de uma casa organizada, em que cada objeto tem o seu lugar. O burguês prefere ficar encapsulado dentro de seu próprio lar lendo lentamente romances sobre a vida que evolui rapidamente lá fora. Assim sendo, o art nouveau se expressa nas residências, através de interiores rebuscados, que serão abolidos com a chegada do modernismo.

Apesar de Baudelaire ser o poeta mais significativo do período, o romance clássico que melhor reflete as contradições decadentistas em relação ao tema "natureza" é $A$ Rebours de Joris-Karl Huysmans, traduzido para o português como Às avessas, e para o inglês como Against Nature. O protagonista do romance, Dês Esseintes, foge de sua vida burguesa para uma casa de campo, alegando estar em busca da natureza. Porém, o resultado é um ambiente totalmente artificial, em que tudo ao seu redor tem uma aparência artificial, e até mesmo o jardim composto de flores verdadeiras revela um aspecto dissimulado. Ao mesmo tempo em que a natureza é recriada, ela é negada.

Um exemplo significativo dessa relação contraditória com a natureza é o trecho em que o protagonista adquire uma tartaruga, viva, para compor a decoração de uma das salas de sua casa; porém, a cor do dorso do animal não combina com o tom do tapete. $\mathrm{O}$ 
protagonista manda então incrustar pedras preciosas coloridas na carapaça da tartaruga. A beleza é aqui alcançada por meio da violação da natureza.

A tartaruga é um ícone do decadentismo, que fomenta a dualidade da lentidão da flânerie como forma de provocação à velocidade das inovações tecnológicas. $\mathrm{O}$ pessimismo dos intelectuais que acreditam que a civilização nos leva a decadência, em conflito com o otimismo difundido pela paz nos lares e na Europa propiciada pelos descobrimentos aliados aos avanços científicos e técnicos, incita a dicotomia de um declínio social em oposição à prosperidade econômica. Já na arquitetura e nas artes, eram duas as abordagens da natureza nesse período; o designer tentava imitar as formas naturais em materiais diversos, ou tentava evocá-las por meio de sensações do fenômeno.

As evocações mais originais e sutis da natureza acontecem nas obras arquitetônicas mais representativas do movimento art nouveau. Seus adeptos ${ }^{15}$ têm em comum os ideais da unidade do edifício, os interiores e a expressão da natureza. A linha ondulada não os limita. As estações de metrô de Paris, de Hector Guimard, são sugestivas tanto nas plantas quanto nos insetos representados, mas não revela uma cópia direta da natureza. Na obra de Charles Rennie Mackintosh, os motivos são baseados na natureza, mas nunca obviamente naturais. Cada designer oferece uma solução diferente ao problema da metamorfose apresentado por Guimard.

As influências desse movimento de vanguarda podem ser identificadas nos movimentos pré-rafaelitas, arts and crafts, rococó, gótico, e no orientalismo. Porém, a fundamentação do art nouveau surge do movimento inglês arts and crafts através do pensamento de seu líder, John Ruskin (1819-1900). Literato interessado em política, economia, arte, geografia, geologia, botânica e muitos outros assuntos, Ruskin reage à falta de poesia do mundo industrial e reivindica o retorno ao artesanato.

De acordo com os ensinamentos de Ruskin, a natureza nos é revelada nas coisas comuns. O movimento arts and crafts exalta os valores de produção da Idade Média, propõe um retorno ao trabalho manual, glorifica a beleza artesanal. As causas da desintegração da cultura artística são fundamentadas, para Ruskin, nas condições econômicas e sociais da produção artística. A arte é o trabalho manual aliado à inteligência humana, enquanto as belas artes são o que as mãos, a mente e o coração do homem fazem juntos.

Ruskin condena o uso da máquina em prol do artesão, defendendo o uso do ornamento, desde que feito à mão. No entanto, o pensador comete um erro comum à sua época, ao confundir as condições da indústria de seu tempo com o conceito abstrato de indústria, e, por conseguinte, transforma um juízo histórico em juízo universal.

A menos perceptível, porém verdadeira, contribuição de Ruskin, está expressa em seus estudos acerca dos elementos da natureza, tais como as rochas, as árvores e as nuvens. Além do pitoresco, esses estudos proporcionam a estrutura que se encontra na base do 'fazer' artístico e antecipam a arte "do povo para o povo"16, promovida por William Morris, em que formas naturais eram imitadas em tapeçarias e papéis de parede, assim como algumas pesquisas do art nouveau que também tiram partido da estilização dos elementos naturais.

Ruskin define arquitetura como "a arte que dispõe e adorna os edifícios construídos pelo homem, para qualquer uso, de tal modo que sua vista possa contribuir para sua saúde mental, para sua eficiência e para seu prazer"17, estabelecendo dicotomias ainda discutidas na atualidade, como utilidade/beleza, e a mais sutil arquitetura/construção.

Em História da Arquitetura Moderna (1989), Leonardo Benevolo lista os fatores que precedem a arquitetura de vanguarda europeia no continente. Entre eles se incluem a 
insatisfação geral com o ecletismo, as novas teorias sobre a arte, os exemplos dos pintores, as condições sociais e o compromisso pessoal.

Sobre as novas teorias sobre a arte, Konrad Fiedler anuncia o ponto de partida dos movimentos de vanguarda: um conceito novo em que a arte é uma experiência ativa, construtiva, um "elemento integrante da moderna concepção do mundo". Como Fiedler abrange a estética desde do classicismo, sua teoria contribui para a queda da autoridade das regras tradicionais. Fiedler promove as discussões da contradição entre a beleza e a arte, e do belo da natureza em oposição ao belo artístico, que retomarei antes da conclusão deste trabalho.

Do exemplo dos pintores, cabe lembrar a relação íntima por meio de troca de resultados entre a obra inovadora dos arquitetos de vanguarda e a dos pintores. Paul Cézanne explica que "a natureza é sempre a mesma, mas nada resta dela, daquilo que parece" e se pergunta o que está por trás do fenômeno natural, além das linhas, objetos, rochas e árvores que se formam. Já a afirmação de Paul Gauguin, de que "quando o artista [...] deseja realizar uma obra criativa, ele não tem necessidade de imitar a natureza, mas deve tomar os elementos da natureza e criar um novo elemento" 18 , sintetiza os preceitos do papel da natureza no movimento art nouveau.

Das condições sociais e do compromisso pessoal, Benevolo reforça que os movimentos inovadores na pintura e arquitetura coincidem com a Belle Époque. $\mathrm{O}$ crescimento econômico favorece a vanguarda, pois oferece mais oportunidades de emprego aos artistas da época. Apesar de tudo, a distância entre sociedade e cultura não se estreita. O movimento é conduzido por poucos artistas em nome de toda a sociedade. Como mencionado, a época é caracterizada pela contradição gerada por indivíduos, ou pequenos grupos, que reivindicam a liberdade pessoal e originalidade. O conflito fica mais óbvio ao relacionar questões teóricas à cada obra individualmente.

Desse lugar, o art nouveau surge espontaneamente e toma forma a partir de suas raízes. O movimento nasce efetivamente na Bélgica com a Casa Tassel de Victor Horta e na decoração da casa de Henry Van de Velde. Na Alemanha, o estilo é conhecido como Jugendstil (estilo da juventude) nomeado pela revista Jugend. Na Áustria, acontece uma abordagem muito particular, representada pelos artistas ligados à Secessão Vienense. A ideia era confrontar a orientação conservadora e historicista vigente; as idéias do movimento de ruptura eram divulgadas na revista Ver Sacrum. O pintor Gustav Klimt e o arquiteto Otto Wagner, que pregam a libertação da imitação, cultuam a palavra 'novo' e levam em conta as condições técnicas modernas, são os nomes de maior destaque do movimento na Áustria. Na Escócia, o movimento consolida-se a partir da atuação da escola de Glasgow, representada por Charles Rennie Mackintosh e o 'grupo dos quatro', que enfatizavam em suas obras a simplificação geométrica. Na Espanha, Barcelona foi outro grande centro com a peculiar obra de Gaudi ${ }^{19}$.

Além dos pensamentos de Ruskin, a figura do francês Samuel Bing foi outra peça chave na evolução dos princípios que dominaram o mundo da arte na virada do século XIX. No artigo L'Art Nouveau ${ }^{20}$ (1902), Bing discute o anacronismo entre as centenas de novas descobertas científicas e a centelha provocada pelas inovações sociais do período, prevendo que o movimento art nouveau teria vida curta.

Bing demonstra preocupação tanto com o uso adequado dos objetos desenvolvidos, quanto com o respectivo aspecto visual, que gera a harmonia entre linhas e cores. $\mathrm{O}$ crítico sinaliza o perigo das imitações rudes, feitas em nome do art nouveau, que proliferam como vegetação parasita, sem considerações às mais elementares regras da lógica; ele ainda critica a estética erroneamente explorada, com objetos distorcidos, sem harmonia, classificados como art nouveau somente para ganhar um tom de vanguarda. 
No artigo L'Art Nouveau ${ }^{21}(1903)$, são listados os princípios $^{22}$ do movimento que, segundo ele, não é um estilo ${ }^{23}$. Os inovadores buscam a total liberdade de expressão artística, no entanto existe um consenso entre eles, que é a aversão à estagnação. Um retorno à natureza livre pode por si só restaurar, e rejuvenescer, os espíritos da época. A partir desse código - considerado infalível - das leis da beleza, os adeptos ao movimento passam a ter condições para enriquecer velhas fórmulas com uma nova força de desenvolvimento, mas são forçados a subordinar a característica geral do meio ambiente, a favor das condições da vida moderna.

Bing abre uma nova discussão que, aliada aos ensinamentos dos ingleses Ruskin e Morris juntamente com a preocupação didática do austríaco Otto Wagner, permite uma melhor compreensão dos interesses em relação à decoração e aos processos de produção dos arquitetos vanguardistas. Segundo Benevolo, essa "transposição de um juízo artístico para o plano teórico" ajuda aqueles que haviam "participado da formação da art nouveau, no clima refinado da Bruxela de fin-de-siecle" na aceitação "das chocantes simplificações dos alemães nos anos que antecedem a guerra mundial"24. Essa transição pode ser ilustrada pelo trecho abaixo extraído da autobiografia de Van de Velde - diretor do Weimar Kunstgewerblicher Institut, futura Bauhaus:

Tal como o mal luta perpetuamente para corromper a virtude, da mesma forma, através de toda a história da arte, um temor maligno procura ingentemente macular ou deformar os mais puros idéias de beleza do homem. $\mathrm{O}$ breve interlúdio da art nouveau, movimento efêmero que não conheceu outra lei senão o próprio capricho foi seguido [...] pelo começo hesitante de um novo estilo disciplinado e proporcional a seus fins, o estilo de nosso tempo. Duas guerras mundiais prolongaram suas dificuldades de crescimento, mas passo a passo prossegue seu caminho consciente para a maturidade. E a maturidade, quando for finalmente atingida, coincidirá com a instauração de uma estética racionalizada, onde a beleza e a forma estejam imunizadas contra as infecções recorrentes do parasita danoso que é a fantasia. ${ }^{25}$

Nessa mesma linha de raciocínio, W. Crane chama o art nouveau de doença decorativa.

O polêmico arquiteto teórico Adolf Loos (1870-1933) compartilha das mesmas idéias de Bing, Velde e Crane, contudo de maneira ainda mais radical. Loos escreve artigos, ministra conferências e publica uma revista ${ }^{26}$, sempre questionando o culto à originalidade, a favor da modéstia e discrição. Para ele, a arquitetura é apenas utilitária e não uma forma de arte. Contradizendo os pressupostos do movimento art nouveau, é também favorável à eliminação de todo ornamento. A ornamentação na arquitetura não passa de um resíduo de hábitos bárbaros. O ornamento seria um resquício da tradição; seria preciso um rompimento com essa tradição para abrir espaço para o novo, que chega com as possibilidades oferecidas pelos modos de produção capitalista. O novo não acontece como uma evolução, mas sim como uma ruptura.

Loos propõe a eliminação de todos os elementos não estruturais, dando lugar aos volumes em alvenaria lisa com aberturas recortadas, coroadas com uma simples cobertura. Exerce influência sobre o arquiteto alemão Walter Gropius, o holandês Jacobus Oud e o ícone francês Le Corbusier. Em uma tentativa de conciliação da dicotomia necessidade/beleza, Gropius, seguindo a linha de Loos, alega que o "valor das coisas não pode ser encontrado na natureza de alguma coisa, mas é produto da indústria do homem"27. 
Benjamin também conta com as ideias de Loos para questionar o rompimento com a "nostalgia da renascença" e a "imagem do homem tradicional, solene, nobre, adornado com todas as oferendas do passado" 28 a favor de um novo homem contemporâneo. No ensaio Experiência e Pobreza, Benjamin relata a maneira como a geração que sobreviveu à primeira guerra mundial ficou "mais pobre em experiências comunicáveis" 29 . O autor fala do surgimento de uma nova forma de miséria a partir do desenvolvimento da técnica, e do surgimento de um conceito positivo de uma nova barbárie.

Aquele quarto encapsulado burguês relatado por Benjamin, impregnado de vestígios que impedem seu habitante de acrescentar algo mais, é o ápice do acúmulo de história pessoal, como se nada mais pudesse ser vivenciado. Entretanto, a partir da proliferação do pensamento de Loos, o art nouveau começa a se esvair rapidamente, dando lugar a uma nova estética modernista. A escola Bauhaus, para abolir esse espaço acumulado, cria um novo espaço onde é difícil deixar rastros, a partir dos novos materiais: o vidro, o aço e o concreto.

Porém, em tom pessimista de quem antevê horrores ainda maiores na eminente segunda grande guerra mundial, Benjamin diz que esse "novo ambiente de vidro mudará completamente os homens" ${ }^{30}$, uma vez que o vidro é "um material tão duro e liso, no qual nada se fixa. É também um material frio e sóbrio. As coisas de vidro não têm nenhuma aura. O vidro é em geral o inimigo do mistério. É também o inimigo da propriedade" 31 .

$\mathrm{O}$ enfraquecimento da experiência da vanguarda que se exaure, e o surgimento dos elementos do movimento moderno, não ocorrem como uma evolução, mas sim como uma 'ponte', em forma de passagem, de transição. Ainda assim, o papel da natureza no movimento art nouveau depende do viés crítico em voga. Apesar de muito criticado pelos modernistas, as frequentes exposições de seus objetos de design em galerias e museus atualmente os universalizam como belos, evocando a discussão kantiana do belo, do bom e do agradável, e contribuindo para a compreensão do lugar da natureza do ponto de vista estético.

Retomo aqui a discussão proposta por Fiedler, em que ele salienta o envolvimento da discussão do belo da natureza e do belo artístico. O belo tem relação com os preceitos das tradições clássicas, enquanto o feio é a ruptura de tais preceitos. Os positivistas chamam a atenção para as relações entre a arte e as ciências naturais e sociais. Fiedler promove a discussão da contradição entre a beleza e a arte; segundo ele,

[...] a beleza diz respeito ao prazer que certas imagens nos provocam, pode provir indiferentemente dos objetos naturais e artísticos e está confinada à esfera prática [...] O belo e o bom deixam-se reduzir ao agradável e ao útil; a arte, por sua vez, "eleva a intuição sensível à consciência, e seu efeito principal encontra-se na forma característica de conhecimento que é por ela oferecida", conhecimento esse que, kantianamente, é concebido como função ativa, ordenadora, "um dos meios que foram dados ao homem para apropriar-se do mundo" $" 32$.

Fiedler estabelece, portanto, que a teoria do belo ou da estética é coisa diversa da teoria da arte.

O art nouveau é representado principalmente por obras arquitetônicas e objetos de design; esses objetos têm uma recepção ótica e tátil e estão mais relacionados com a sensação sensorial do que à reflexão. Assim sendo, o design se aproxima mais da ordem dos sentidos, do agradável. Já uma obra arquitetônica envolve o agradável, mas pode 
também levar ao prazer que está na reflexão, envolvendo o belo. A arte, para ser bela, tem que ter elementos de composição, como a música - e o ornamento, pelo menos, para Kant.

Já o bom é traduzível em conceitos que levam a um julgamento. A natureza petrificada a favor dos ornamentos faz lembrar a noção de kitsch, ou camp. Sontag sugere que no camp, os "exemplos puros [...] não são intencionais, são extremamente sérios: o artesão art nouveau que fabrica uma lamparina com uma serpente enrolada não o faz por brincadeira, nem tenta nos fascinar. Diz-se apenas, com toda seriedade: eis o oriente!"33. Em seu julgamento, Sontag estabelece que o art nouveau não é bom, é ruim. E complementa com a máxima: "é belo porque é horrível"34.

A argumentação de Sontag incita um dos contrastes mais decisivos aos temas do movimento - a perda da aura. A aura, segundo Benjamin, "é uma figura singular, composta de elementos espaciais e temporais: a aparição única de uma coisa distante, por mais perto que esteja"35. A necessidade irresistível de ter algo próximo, de possuir esse objeto, atrofia a aura da obra de arte quando reproduzida tecnicamente. Benjamin explica que em sua essência, a obra de arte sempre foi reprodutível; o que o homem faz sempre pôde ser imitado por outros visando o lucro ${ }^{36}$. Não obstante a distancia temporal, essa noção de 'desauratização', provocada pela reprodução em série e pelo uso de materiais duros, tais como o vidro e o aço, dialoga com aquela discussão entre a produção artesanal e a industrialização de Ruskin, o que seria assunto a ser desenvolvido em um outro artigo.

Em um breve espaço no tempo, o uso exacerbado do ornamento com inspirações na natureza, à moda do movimento art nouveau na arquitetura, cede espaço a uma total aversão ao ornamento, como proposto pelo arquiteto alemão Adolf Loos, que culmina na escola Bauhaus. A palavra 'ponte', usada por Grady, parece pertinente a essa transição, que não é uma evolução. Tal transição insinua também a dicotomia ornamento natural/organicidade - tema que pode ser explorado em outro trabalho.

Se por um lado, o tom dicotômico presente nas expressões artísticas do movimento art nouveau tira a força do movimento, por outro a produção de objetos em série é fomentada pelo atrito causado por essas dualidades, entre elas a prosperidade e o declínio social, o otimismo e o negativismo, a velocidade e a lentidão, a beleza e a utilidade ou necessidade, a arquitetura e a construção e, finalmente, a forma e a função. Apesar das contradições do movimento art nouveau - progressista do ponto de vista estético, e conservador em sua ligação com a burguesia em crise - estabelecerem uma vida curta ao movimento, a tentativa do art nouveau em fazer com que a arte se entendesse com a técnica é um marco na arquitetura, ao democratizar a beleza por meio do design industrial e de produtos.

Para Oscar Wilde, "quanto mais estudamos a arte, menos nos interessa a natureza" 37 . Os ornamentos arquitetônicos produzidos a partir de materiais duros, tais como o vidro e o ferro, não têm vida ou movimento; a natureza, petrificada e reduzida ao ornamento, perde todo seu dinamismo. A beleza é alcançada por meio da violação da natureza - ao mesmo tempo em que ela é recriada, é negada. A "natureza encontrada na modernidade é sempre fragmentada, artificial, marcada por manifestações culturais ou artísticas" ${ }^{38}$. No art nouveau, a natureza é intencionalmente fake.

O lugar da natureza no movimento art nouveau é o da inspiração. Os elementos da natureza não devem ser copiados, ou imitados, e sim sugeridos, revelando o que está por trás do fenômeno natural através de suas linhas estilizadas. Como sintetizado por Gauguin, o artista toma emprestado os elementos da natureza para criar algo totalmente novo. A artificialidade no movimento art nouveau é patente. 
Abstract: Departing from the thesis that the over exploitation of organic ornaments characteristic of the art nouveau, would not be a return to the nature, but rather the foreshadowing of a theme aversion, this article aims to investigate the role of nature within this movement which took place in the turn of the nineteenth century, in order to understand its place under an aesthetic view.

Keywords: nature; art nouveau; architecture.

\section{Referências Bibliográficas}

BAUDELAIRE, Charles. Sobre a modernidade. Org. Teixeira Coelho. 1996. Rio de Janeiro: Paz e Terra, 2007.

BENEVOLO, Leonardo. História da Arquitetura Moderna. Trad. Ana M. Goldberger. São Paulo: Editora Perspectiva, 1989.

BENJAMIN, Walter. Obras escolhidas: Magia e técnica, arte e política. São Paulo: Brasiliense, 1985.

BENJAMIN, Walter. Obras escolhidas III: Charles Baudelaire. São Paulo: Brasiliense, 1989.

BING, Samuel. Artistic America, Tiffany Glass, and Art Nouveau. Cambridge, London: The MIT Press, 1970.

COLIN, Silvio. A Poética do Art Nouveau na Arquitetura. Disponível em: $<$ http://coisasdaarquitetura.wordpress.com/2011/07/09/a-poetica-do-art-nouveau-naarquitetura/>. Acesso: 03 de maio, 2012.

CUDDON, J.A. The Penguin Dictionary of Literary Terms and Literary Theory. Disponível em: <http://pt.scribd.com/doc/9406738/Literature-Penguin-Dictionary-ofLiterary-Terms-and-Literary-Theory-4Th-Ed-Text>. Acesso: 24 jul. 2012.

ECO, Humberto. História da Beleza. Trad. Eliana Aguiar. Rio de Janeiro, São Paulo: Record, 2004.

ECO, Humberto. História da Feiúra. Trad. Eliana Aguiar. Rio de Janeiro, São Paulo: Record, 2007.

The Victorian Web. John Ruskin. Disponível em: <http://www.victorianweb.org/authors/ruskin/index.html>. Acesso: 15 de maio, 2012.

GRADY, James. Nature and the Art Nouveau. The Art Bulletin, Vol. 37, No. 3, p. 187192, Set, 1955.

HUYSMANS, Joris-Karl. Às avessas. São Paulo: Companhia das Letras, 1987. 
MADSEN, Stephen T. The Art Nouveau Style: a comprehensive guide with 264 illustrations. NY: Dover Publications, 2002.

SONTAG, ${ }^{39}$ Susan. Notes on Camp. 1964. Disponível em: <http://www.math.utah.edu/ lars/Sontag::Notes\%20on\%20camp.pdf> . Acesso: 23 jul. 2012.

SCHOPFER, Jean. L'Art Nouveau: An Argument and De-fence. The Craftsman, No. IV, p. 229, Julho, 1903.

\section{Notas}

1 SCHLEGEL, Friedrich. Fragmento [116] do Athenaeum (1798). In: SCHLEGEL, Friedrich. O dialeto dos fragmentos. Tradução, apresentação e notas de Márcio Suzuki. São Paulo, Iluminuras, 1997, p. 64-5.

${ }^{2}$ CUDDON. The Penguin Dictionary of Literary Terms and Literary Theory, p. 77.

${ }^{3}$ COLIN. A poética do art nouveau na arquitetura, s/p.

${ }^{4}$ ECO. História da Beleza, p. 369.

${ }^{5}$ SCHOPFER. L'Art Nouveau: An Argument and De-fence, p. 229.

${ }^{6}$ No original: "The Art Nouveau has reverted to Nature, that it might discover new beauty". GRADY. Nature and the Art Nouveau, p. 187.

${ }^{7}$ MADSEN. The Art Nouveau Style, p. 185.

${ }^{8}$ No original: "It is an important bridge between the confused archaeological expressions of the nineteenth century and contemporary architecture". GRADY. Nature and the Art Nouveau, p. 192.

${ }^{9}$ SONTAG apud ECO, História da Feiúra, p. 411.

10 As palavras camp e kitsch são comumente tratadas como sinônimas, ambas tem relação com qualquer objeto que tenha valor estético. Entretanto kitsch se refere especificamente a obra em si, enquanto camp é a maneira de performance. Camp é sempre uma maneira de consumir cultura "entre aspas”. ECO. História da Feiúra, p. 418.

${ }^{11}$ No original: "Nature is a big book from which we can draw inspiration, and it is in that book that we must look for principles, which, when found have to be defined and applied by the human mind according to human needs". GRADY. Nature and the Art Nouveau, p. 188.

${ }^{12}$ BENJAMIN. Obras escolhidas III, p. 9-102.

${ }^{13}$ BENJAMIN. Obras escolhidas III, p. 43.

${ }^{14}$ BENJAMIN. Obras escolhidas III, p. 43-4.

${ }^{15}$ Os principais nomes são: Victor Horta na Bélgica, Hector Guimard na França, Charles Rennie Mackintosh na Escócia, Louis Sullivan nos EUA e Antonio Gaudi na Espanha.

${ }^{16}$ BENEVOLO. História da Arquitetura Moderna, p. 198.

${ }^{17}$ BENEVOLO. História da Arquitetura Moderna, p. 198.

${ }^{18}$ BENEVOLO. História da Arquitetura Moderna, p. 270.

${ }^{19}$ De acordo com o arquiteto Silvio Colin, "a obra de Antonio Gaudi é muito próxima do art nouveau, pelo uso que faz dos motivos naturais, florais e formas orgânicas. Entretanto sua obra é tão pessoal e subjetiva que talvez não caiba em nenhum estilo. Ela ultrapassa os limites do art nouveau, na medida em que possui além do simbolismo e do lirismo ornamental desta, características de expressionismo e um trabalho intenso com a lógica estrutural e elemental da arquitetura. Certamente, para um entendimento melhor desta 
personalidade singular e sua obra, faz necessário um estudo isolado”. COLIN. A poética do art nouveau na arquitetura, s/p.

${ }^{20}$ Publicado pela primeira vez na revista especializada The Architectual Record em 1902 e republicado em BING. Artistic America, Tiffany Glass, and Art Nouveau, p. 213-24.

${ }^{21}$ Publicado no periódico The Craftsman em outubro de 1903 e republicado em BING. Artistic America, Tiffany Glass, and Art Nouveau, p. 227-51.

${ }^{22}$ Os princípios são: a sujeição do objeto a um sistema rígido de lógica em relação ao seu uso e material; a ênfase da estrutura orgânica pura; a demonstração clara de cada parte na arquitetura do objeto; e a prevenção da falsidade de um luxo fictício, que consiste em falsificar os materiais e exagero no uso dos ornamentos. BING. Artistic America, Tiffany Glass, and Art Nouveau, p. 228-30.

${ }^{23}$ BING. Artistic America, Tiffany Glass, and Art Nouveau, p. 227.

${ }^{24}$ BENEVOLO. História da Arquitetura Moderna, p. 282.

${ }^{25}$ VAN de VELDE apud BENEVOLO. História da Arquitetura Moderna, p. 286.

${ }^{26}$ O Outro - periódico para a introdução da civilização ocidental na Áustria.

${ }^{27}$ BENEVOLO. História da Arquitetura Moderna, p. 302.

${ }^{28}$ BENJAMIN. Experiência e Pobreza, p. 116.

${ }^{29}$ BENJAMIN. Experiência e Pobreza, p. 114-5.

${ }^{30}$ BENJAMIN. Experiência e Pobreza, p. 117.

${ }^{31}$ BENJAMIN. Experiência e Pobreza, p. 117.

${ }^{32}$ BENEVOLO. História da Arquitetura Moderna, p. 268.

${ }^{33}$ SONTAG apud ECO, História da Feiúra, p. 418.

${ }^{34}$ SONTAG apud ECO, História da Feiúra, p. 411.

${ }^{35}$ BENJAMIN. Obras escolhidas III, p. 170.

${ }^{36}$ BENJAMIN. Obras escolhidas III, p. 170.

${ }^{37}$ No original: "My own experience is that the more we study Art, the less we care for Nature". ECO. História da Beleza, p. 340.

${ }^{38}$ Nota em aula durante o seminário da colega Bruna Fontes Ferraz. 